\title{
Study the FTIR of Hydroxyapatite Addi- tive to Heat Cured Acrylic Resin
}

Zena J Hassan BDS

Nadira A Hatim BDS, MSc (Prof.)

Amer A Taqa

BSc, MSc, PhD (Prof)
Department of Prosthodontic

College of Dentistry, University of Mosul

Department of Prosthodontic

College of Dentistry, University of Mosul

Department of Dental Basic Science

College of Dentistry, University of Mosul

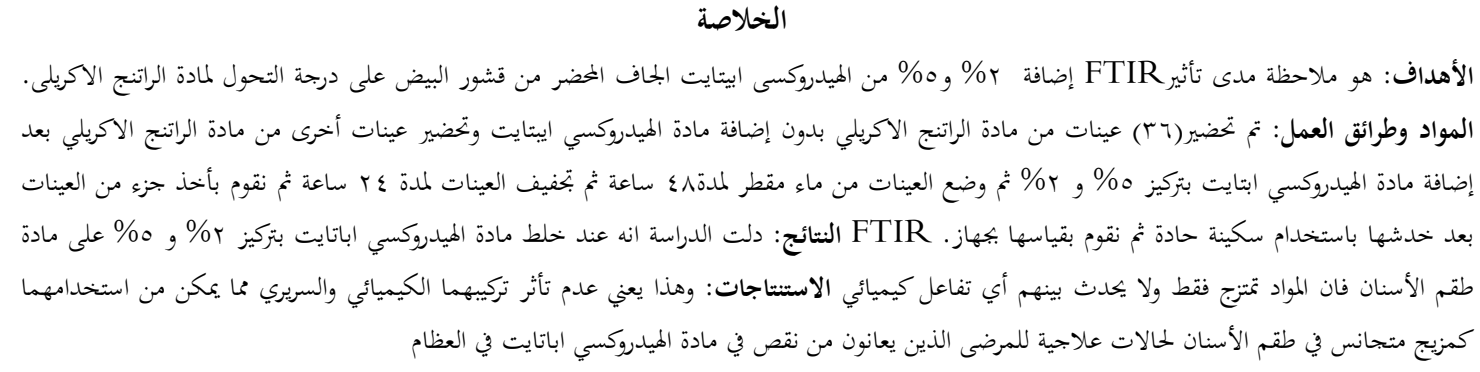

\section{ABSTRACT}

Aims: To evaluate the FTIR of Hydroxyapatite additives $2 \%$, and $5 \%$ of dry (HAP) prepared from egg shells to the polymer. Materials and Methods: Thirty six specimens of heat cured acrylic resin and other specimens of heat cured acrylic resin with $2 \%$ and or $5 \%$ prepared then immersed in distilled water for 48 hours then dried for 24 hours then scratched with sharp knife and measured by FTIR spectra. Results: The result showed when adding 2\% \&/or 5\% hydroxy apatite to heat cured acrylic resin denture base material resulting a homogenous mixture, without chemical reaction in between and without changes of acrylic resin properties. Conclusion: they can be used together in patients with bone hydroxy apatite deficiency.

Keywords: FTIR test, Dry (HAP)

Hassan ZJ, Hatim NA, Taqa AA,. Study the FTIR of Hydroxyapatite Additive to Heat Cured Acrylic Resin. Al-Rafidain Dent J. 2014;14(1), 32-36.

Received: 12/8/2012 Sent to Referees: 13 /8/2012 Accepted for Publication: 9/10 / 2012

\section{INTRODUCTION}

During curing of acrylic resin, polymerization is initiated by free radicals from the benzoyl peroxide. As polymerization proceeds, the reaction never reach $100 \%$ conversion i.e. conversion of monomer into polymer is not completed. The degree of conversion is the most important criterion that account for un reacted residual monomer levels ${ }^{(1)}$.The final degree of conversion of a resin depends on the chemical structure of the dimethylmethacrylate monomer and the polymerization conditions i.e., atmosphere, temperature, light intensity and photo initiator concen-

\section{tration $^{(2)}$.}

The degree of conversion is expressed as percentage of un reacted $\mathrm{C}=\mathrm{C}$ bonds ${ }^{(3)}$. In general raised temperature and extended polymerization time showed improved conversion and lowering the monomeric release. Increasing time at boiling during curing result in improvement in studied properties specially the degree of conver$\operatorname{sion}^{(4)}$. The degree of conversion of dimethyl methacrylates may be improved if the distance between the methacrylate groups is long, and the molecular weight is high, respectively. High conversion is not a goal in itself, however, If the monomer is very 
flexible and not sufficiently bulky, the degree of conversion will be high, but the mechanical properties will be poor ${ }^{(5)}$. Water bath and microwave post polymerization (The material was polymerized in a microwave oven and the kinetics of release of residual monomer in water was evaluated by spectrophotometric method up to $24 \mathrm{~h}$ ) treatments decrease the residual monomer of auto polymerized acrylic resin $^{(6)}$. Fourier transform infrared spectroscopy (FTIR) is a widely used analytical technique that is routinely applied to the characterization of biomaterials. However ,preparing specimens of biomaterials for infrared spectroscopy is often a tedious process. The main sampling problem in FTIR characterization of biomaterials is that nearly all solid materials are too opaque in their normal forms for direct transmission analysis in the mid-infrared region. This problem can be solved by reducing the optical density of specimens to a suitable level by employing various sampling techniques ${ }^{(7)}$. These procedures, however, can alter the nature of the sample and are time consuming. Limited amount of information is available within the near infra-red spectral-region, whereas the mid infra-red region provides most spectral bands for required characterization. ${ }^{(8)}$ So photo acoustic sampling (PAS) provide solution to these problems and the materials can be easily analyzed by PAS-FTIR sampling without the need to reduce the particle size or dilute with $\mathrm{KBr}$, allowing the analysis of biomaterial in a physiological condition ${ }^{(9)}$.Microwave post polymerization resulted in a higher degree of conversion and higher flexural strength of an auto polymerizing acrylic resin repair material. ${ }^{(10)}$

\section{MATERIALS AND METHODS}

Hydroxyapatite (HAP) was synthesized by the slow addition of $0.6 \mathrm{M} \mathrm{H}_{3} \mathrm{PO}_{4}$ (Phosphoric acid) to the aqueous (molar ratio) suspension of $\mathrm{CaCO} 3$ (Calcium carbonate) under constant stirring. The result- ant was filtered and dried at $50^{\circ} \mathrm{C}$ for 3 hours and sintered in air atmosphere at $1100^{\circ} \mathrm{C}$ for 2 hours. To obtain principal HAP critical control of the $\mathrm{pH}$ of the reaction and concentration of the reactant is required. The final product was characterized for its crystalline and phase behavior through instrumentation techniques by infrared spectrophotometer and compare with standard as control .

$$
10 \mathrm{Ca}(\mathrm{OH})_{2}+6 \mathrm{H}_{3} \mathrm{PO}_{4} \rightarrow
$$$$
\mathrm{Ca}_{10}(\mathrm{PO} 4)_{6}(\mathrm{OH})_{2}+18 \mathrm{H}_{2} \mathrm{O}
$$

The degree of conversion of the materials under investigation was determined by Fourier transform infrared spectroscopy (FTIR) thirty six specimens of heat polymerizing resin with dimension of $10 \times 4 \times 4( \pm 0.03) \mathrm{mm}$ were prepared, and divided into three groups (First group Control, Second group with HA 2\%, Third group with HA 5\%) after that the specimens were finished with stone bur and sand paper to remove any gypsum product on their surfaces then they polished and stored in distilled water at $37( \pm 1) \mathrm{C}$ for 48 hours $^{(2)}$. After 48 hours, the specimens were removed from water and dried in air and then scraped using a sharp, clean and sterile wax knife to obtain powder of the polymerized specimens. Then $300 \mathrm{mg}$ of the sample powder was grinded finely, under anhydrous conditions, in an agate mortar. This powder is then thoroughly mixed with 100-200 $\mathrm{mg}$ of oven -dried, spectral-grade; 100-200 mesh potassium bromide powder. The mixture pellets is then mounted on a holder and placed in the sample beam of spectrometer ${ }^{(3)}$. The FTIR spectra was carried by Tensor 27 FTIR spectrophotometer.

\section{RESULTS}

Results of FTIR test shown in figures (1-3). In the IR charts two important absorbance peaks appeared (the absorbance of the $\mathrm{C}=\mathrm{C}$ band from the methacrylate group which appear around $1640 \mathrm{~cm}^{-1}$ and the absorbance peak of the $\mathrm{C}=\mathrm{O}$ from the ester group appear around $1720 \mathrm{~cm}^{-1}$ ). 


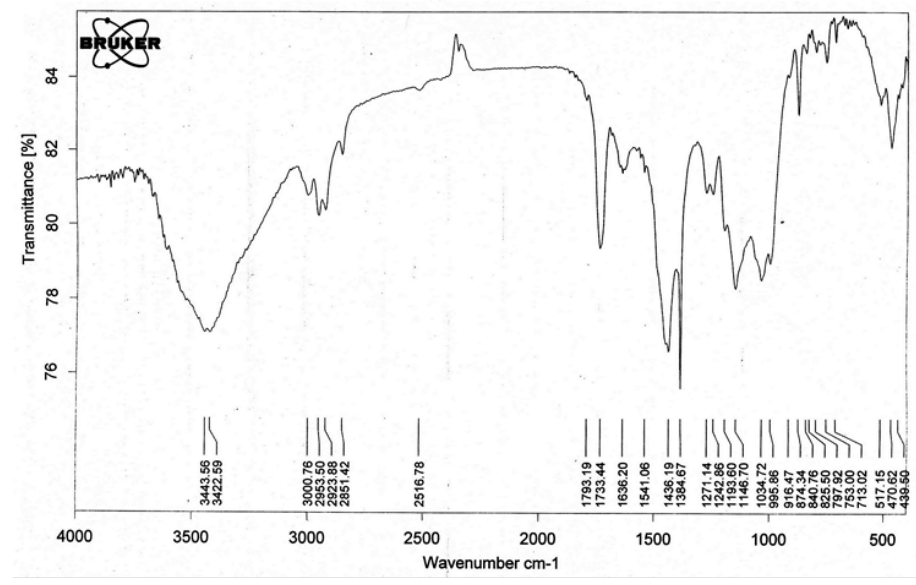

Figure (1): Infrared spectrometer chart of the monomer (methyl methacrylate),Control acrylic resin only.

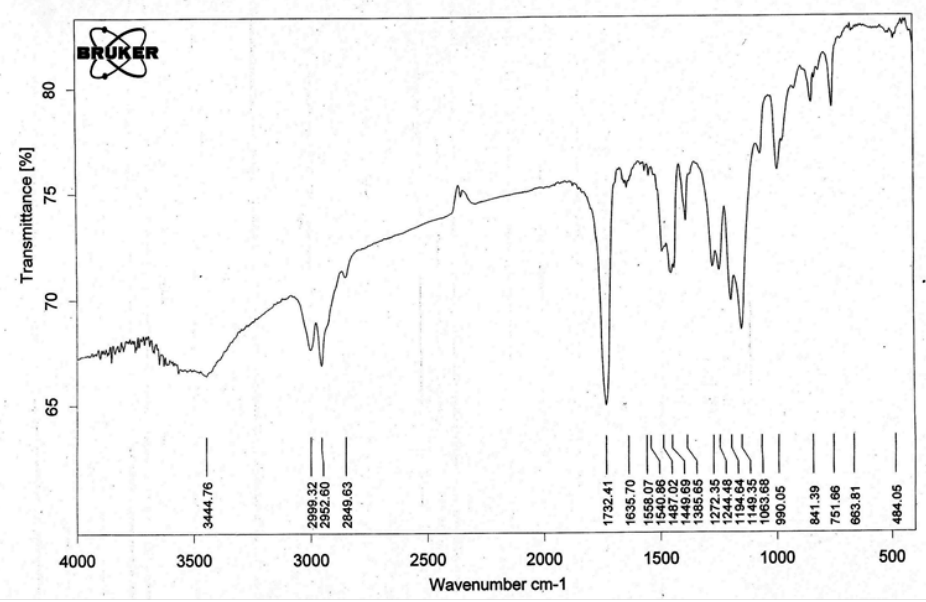

Figure (2): Infrared spectrometer chart of the monomer (methyl methacrylate), Acrylic resin with 2\% hydroxyapatite.

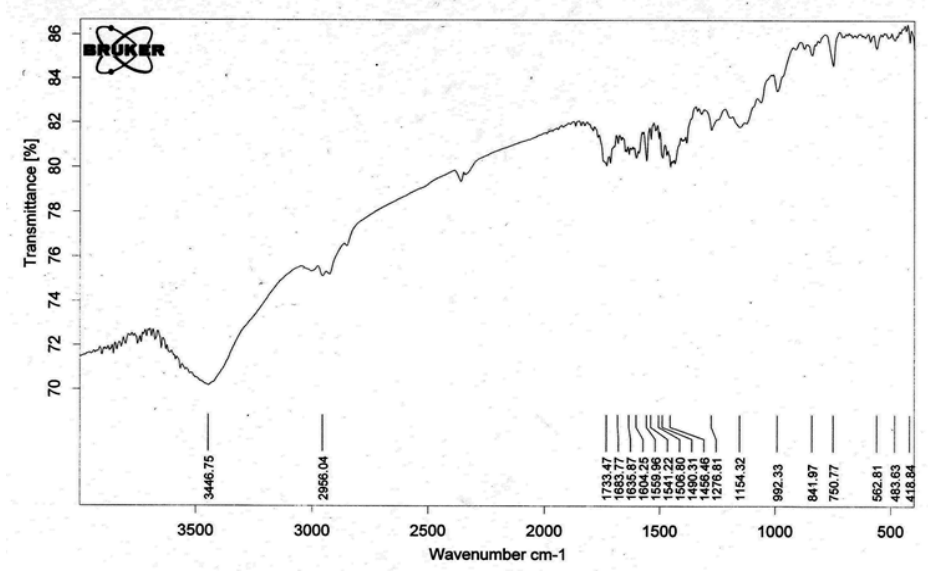

Figure (3): Infrared spectrometer chart of the monomer (methyl methacrylate), Acrylic resin with 5\%hydroxyapatite. 


\section{DISCUSSION}

Fourier transform infrared spectroscopy (FTIR) is a widely used analytical technique that is routinely applied to the characterization of biomaterials. Hydroxyl stretch is observed at $3569 \mathrm{~cm} \sim 1$ in the spectra of synthetic commercial hydroxyl apatite.

The IR spectrum of raw HA powder are showed. The broad peak ranging from $3300-3600 \mathrm{~cm}^{-1}$ can be explained owing to $\mathrm{O}-\mathrm{H}$ group stretch vibration. The band at $1450 \mathrm{~cm}^{-1}$ is assigned to the $\mathrm{CO}_{3}{ }^{2-}$ stretching. An intense $\mathrm{PO}_{4}{ }^{3-}$ peak appeared at $1048 \mathrm{~cm}^{-1}$. Additional phosphate group bands are found in the region 963, 875, 633 and $472 \mathrm{~cm}^{-1}$, a sharp peak of $\mathrm{OH}$ stretch vibration band appeared at $3570 \mathrm{~cm}^{-1}$ and a less intense $\mathrm{CO}^{3-}$ peak appeared at $1450 \mathrm{~cm}^{-1(11)}$.

An intense $\mathrm{PO}_{4}{ }^{3-}$ peak appeared at $1048 \mathrm{~cm}^{-1}$. The additional phosphate peaks are found in the region 1110, 975, 600 and $470 \mathrm{~cm}^{-1(11)}$.

The C-O-C peak at $1254,1200 \mathrm{~cm}^{-1}$ and an intense phosphate peak is found is found at $1040 \mathrm{~cm}^{-1}$. The additional phosphate group bands at $810 \mathrm{~cm}^{-1}$ and $757 \mathrm{~cm}^{-}$ 1 . In this spectrum, there is no peak at $2270 \mathrm{~cm}^{-1(11)}$.

The FT-IR spectrum of PMMA (Figure 1) indicates the details of functional groups present in the synthesized PMMA. A sharp intense peak at $1731 \mathrm{~cm}^{-1}$ appeared due to the presence of ester carbonyl group stretching vibration. The broad peak ranging from $1260-1000^{-1}$ can be explained owing to the $\mathrm{C}-\mathrm{O}$ (ester bond) stretching vibration. The broad band from $950-650 \mathrm{~cm}^{-1}$ is due to the bending of $\mathrm{C}-\mathrm{H}$. The broad peak ranging from 3100$2900 \mathrm{~cm}^{-1}$ is due to the presence of stretching vibration ${ }^{(12)}$.

Figures(2 and 3) shows the IR spectrum of HAP/PMMA. The band at 3000 $\mathrm{cm}^{-1}$ is assigned to $\mathrm{CH}_{3}$ stretch vibration. A very strong band appeared at $1735 \mathrm{~cm}^{-1}$ belongs to the carbonyl group,. Band at $2940 \mathrm{~cm}^{-1}$ is from $-\mathrm{CH}_{2}$ stretch vibration. The C-O-C peak at $1254,1200 \mathrm{~cm}^{-1}$ and an intense phosphate peak is found is found at $1040 \mathrm{~cm}^{-1}$. The additional phosphate group bands at $810 \mathrm{~cm}^{-1}$ and $757 \mathrm{~cm}^{-1}$. The FT-IR spectra provide strong proof that the functionalized PMMA were actually grafted to HAP through In the spectra, therefore, a PMMA spectrum is clearly recognizable ${ }^{(11)}$. From the FTIR charts for control and heat cured acrylic resin after adding hydroxyl appetite they showed there are no any change in the region of bands for $\mathrm{C}=\mathrm{C}$ and $\mathrm{C}-\mathrm{C}$ to polymer before and after addition of (HA) this indicate there is no chemical reaction occurred and this mean there are no any conversion factor happen but the additive minimize the residual monomer.

\section{CONCLUSION}

The addition of $2 \%$ \&/or 5\% hydroxyapatite to heat cured acrylic resin denture base material resulting a homogenous mixture, without chemical reaction.

\section{REFERENCES}

1. Nomoto R, Asada M, Mc cabe JF and Hirano S. Light exposure required for optimum conversion of light activated resin system. Dent Mater. 2006; 22:1135-1142.

2. Urban VM, Mashado AL, Vergani CE, Jorge EG , Santos LP, Leite ER and Canevarolo SV. Degree of conversion and molecular weight of on denture base and three reline submitted to post -polymerization treatments. Mat Res. 2007; 10:1-13.

3. Parikh V.M. Absorption spectroscopy of organic molecules Addison-wasly co. 1974; PP.1-43.

4. Sideridou ,V. Tserki, G. Papanastasiou. Effect of chemical structure on degree of conversion in light-cured dimethacrylate-based dental resins. Biomaterials.2002; 23:1819-1829.

5. Blagojevic V, Murphy VM. Microwave polymerization of denture base materials. A comparative study. J Oral Rehabil.1999;26:804-808.

6. Azzarri Mj, Cortizo MS and Alessandrini JL. Effect of the curing condition on the properties of an acrylic denture base resin, microwave polymerized. $J$ Dent.2003; 31:463-468 .

7. Cekic-negas I, Ergun G, Vallittu PK, Lassila LV. A comparison of monomer conversion and inorganic filler content in visible light-cured denture resin. Dent mater. 2008; 8:274-277. 
8. Osborne BG. and Fearrn T. ÔÔNearinfrared spectroscopy in food analysis (Longman Scientibc and Technical, Essex, 1986).

9. Rehman and Bonfield W. Characterization of hydroxyl apatite and carbonated apatite by photo acoustic FTIR spectroscopy. $J$ mater scie. 1997; 8:1-4.

10. Shin D, and Rawls HR. Degree of conversion and color stability of the light curing resin with new photo initiator systems. Dent Mater. 2009;
25:1030-1038.

11. Krithiga G, Psastry TH. Preparation and characterization of novel bone graft composite containing bone ash egg shell powder. Bull. Mater. Sci. 2011; 34 (1): 177-181

12. Balamurugan A, Kannan S, Selvaraj V, and Rajeswari S. Development and Spectral Characterization of Poly (Methyl Methacrylate) / Hydroxyl apatite Composite for Biomedical Applications. Trends Biomater. Artif. Organs. 2004; 18 (1):41-45. 